\title{
Sand Armor: How it Provides Plants with an Edge Up in Survival
}

\section{Jennifer Roth}

\begin{abstract}
Plants have evolved a dizzying array of morphological and biochemical defenses; a deceptively simple one involves sand. Some plants actively coat themselves in sand, termed psammophory, as an ingenious adaptation for survival. While the functional significance of psammophory is understudied, experimental data from Abronia latifolia and Navarretia mellita suggests that it acts as a mechanical defense against herbivory within dune habitats. This defense stems from both the damaging and non-nutritive properties of sand and the lasting detrimental effects it has on herbivore physiology. While sand armour may seem like an unusual adaptation, it certainly can deter herbivores by giving them something to chew on.
\end{abstract}

No one likes getting covered in sand; it's coarse, rough, irritating, and gets everywhere. Yet for some plants, having a sandy coating could mean the difference between life and death. Living in a desert is rough. Organisms must survive through intense heat and solar radiation, low or variable precipitation, and meagre resources (Evert \& Eichhorn, 2013). On top of that, plants must also spend energy defending themselves against attack; being the only primary producers in these habitats puts a target on their back. Since plants form the basis of most terrestrial food webs, intense herbivory has led to the evolution of ingenious plant defenses (Agrawal, 2006). One of these secrets for survival is sand (LoPresti \& Karban, 2016).

Covering oneself in sand, termed psammophory, occurs when plants actively and regularly entrap sand onto the surfaces of their above-ground tissue, such as leaves, stems, or flowers (Jürgens, 1996; LoPresti \& Karban, 2016). Entrapment is accomplished by either excreting a sticky substance from their epithelial cells or growing dense glandular trichomes, which are outgrowths of the epidermis, or outermost "skin," of the plant which can secrete viscous metabolites (Evert \& Eichhorn, 2013; Jürgens, 1996; Lev-Yadun, 2006; LoPresti \& Karban, 2016). Sand is scattered over the plants via wind or substrate disturbances and sticks to the excretions or trichomes forming an outer barrier (Jürgens, 1996; LoPresti \& Karban, 2016).

Psammophorous "sand armour" is geographically widespread and occurs in a surprising number of plants (Jürgens, 1996; LoPresti \& Karban, 2016; Neinhuis et al., 1996). It is observed in over 200 species throughout the world, although mainly concentrated in sandy or dusty habitats such as coastal or desert dunes (Jürgens, 1996; LoPresti \& Karban, 2016; Neinhuis et al., 1996). With such a widespread occurrence, one must beg the question of why so many plants have developed sand armour? How could it possibly benefit them?

The adaptive advantage of psammophory in plants is understudied and lacks rigorous experimental research (LoPresti \& Karban, 2016). However, it has been hypothesized to provide a myriad of benefits to a plant because it acts as an outer barrier that can provide either physiological or ecological benefits (Jürgens, 1996). Sand could potentially protect against physical damage during sandstorms, reduce water loss and exposure to solar radiation, reduce

Vol. 5(1) | DOI: https://doi.org/10.31542/muse.v5i1.2023 


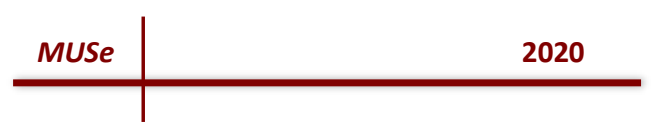

surface temperature if the substrate had a high albedo, or reduce herbivory (Jürgens, 1996; Lev-Yadun, 2007; LoPresti \& Karban, 2016; Neinhuis et al., 1996).

The anti-herbivore function of sand armour may occur through two mechanisms: camouflage and unpalatability (Jürgens, 1996; Lev-Yadun, 2007; LoPresti \& Karban, 2016; Neinhuis et al., 1996). A dusting of sand could allow a plant to blend into the background more effectively, making it more difficult for visually-oriented herbivores to locate them (Jürgens, 1996; Lev-Yadun, 2007; Neinhuis et al., 1996). Further, sand armour could mechanically deter herbivores by being unpleasant to eat, a theory that is gaining traction within the research community (Jürgens, 1996; Lev-Yadun, 2007; LoPresti \& Karban, 2016; LoPresti et al., 2018; Neinhuis et al., 1996).

Previously, the camouflage and unpalatability mechanisms of psammophory were mainly discussed theoretically as experimental data was lacking. Then Dr. Eric LoPresti and Dr. Richard Karban of the University of California decided to get the dirt on this adaptation by experimenting on two species Abronia latifolia and Navarretia mellita, both of which are native to the United States (LoPresti \& Karban, 2016).

Abronia latifolia, known as sand verbena, is a common dune plant found throughout the coast of California (LoPresti \& Karban, 2016). Its short, glandular trichomes facilitate sand entrapment over most of its surface, except for the tops of the leaves, which are only sparsely sandy. A variety of vertebrate and invertebrate herbivores forage on $A$. latifolia. These include deer mice, snails, and leaf-mining caterpillars wherein the larvae feed on the inner leaf tissues. N. mellita is a weedy species endemic to California and can be seen along roadsides, ditches, and eroded areas. It has glandular inflorescences, or flower clusters, that are eaten by small mammals like black-tailed jackrabbits.

Dr. LoPresti and Dr. Karban (2016) experimentally tested whether psammophory was an effective anti-herbivore defense strategy in these plants due to either its unpalatability or camouflaging abilities. They accomplished this through sand addition and removal manipulation and quantified the resulting herbivore damage. Experimental sand removal performed on $A$. latifolia showed that sand presence significantly deterred herbivory and that the amount of chewing herbivory roughly doubled when sand was removed (LoPresti \& Karban, 2016). Experimental addition of substrate to $N$. mellita showed similar results, as sand-covered inflorescences had significantly less herbivore damage and a higher degree of inflorescence maturity. Overall, sand-covered tissue was less preferred by the majority of externally feeding mammalian, gastropod, and arthropod herbivores.

Coloured sand was used to study the mimetic camouflage hypothesis, with green sand to match the plant's colour and brown sand to match the surrounding substrate (LoPresti \& Karban, 2016). No significant difference in herbivory between green sand-coated plants and brown sand-coated plants was found, suggesting that camouflage was not a driving factor in reducing herbivory within these populations. Sand armour's anti-herbivore mechanism was therefore mainly due to the sand's unpalatability.

Crystalline particulates, such as silicon dioxide, can deter both vertebrate and invertebrate herbivores because it is a non-nutritive and damaging substance (LoPresti et al., 2018; Lucas et al., 2014; Massey \& Hartley, 2009). Why psammophory was such an effective anti-herbivore defense in A. latifolia was tackled in a follow-up study by Dr. LoPresti and colleagues (2018). They examined how the sand armour of $A$. latifolia affected the preference and performance of 
the white-lined sphynx caterpillar (Hyles lineata). Sphynx caterpillars feed on the entire leaf, starting from the outside in, which results in a large amount of sand ingestion. The mechanical and non-nutritive properties of sand synchronously protect plants against sphynx caterpillar grazing though both physical deterrence and by causing detrimental physiological effects (LoPresti et al., 2018). Chewing on sand covered tissue causes extensive wear to herbivore mouthparts, consequently reducing feeding efficiency (LoPresti et al., 2018; Lucas et al., 2014; Massey \& Hartley, 2009). Additionally, ingesting large amounts of sand results in lower pupal weight, longer development time, and slower growth rates because it confers no nutrition to the herbivore (LoPresti et al., 2018; Lucas et al., 2014; Massey \& Hartley, 2009). Not surprisingly, the caterpillars in Dr. LoPresti and colleagues' (2018) study avoided sand-covered plants if given a choice.

While humans may detest getting covered in sand, its annoying properties can serve as a valuable physical defense to dune-dwelling plants. Psammophory has a wide geographical distribution and can provide a multitude of benefits or secondary effects in different habitats, so no single ecological benefit may be correlated with its evolution (Jürgens, 1996). However, experimental data suggests that psammophory plays a large role in herbivore defense (LoPresti \& Karban, 2016; LoPresti et al., 2018). Although substrate-induced camouflage can prevent detection, mechanical defenses play an important role in thwarting herbivory (LoPresti \& Karban, 2016; LoPresti et al., 2018; Massey \& Hartley, 2009). Sand ingestion causes mouthpart wear and slower growth rates in external leaf chewers, providing a good incentive to avoid sand-covered plants (LoPresti et al., 2018). If you have ever had your mouth open as a dustfilled wind blew in your face or fallen face-first on the beach, you could appreciate the mechanical deterrence eating sand prompts. 


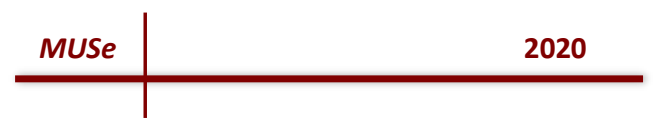

\section{References}

Agrawal, A. A. (2006). Macroevolution of plant defense strategies. TRENDS in Ecology and Evolution, 22(2), 103-109.

Evert, R. F., \& Eichhorn, S. E. (2013). Raven biology of plants. $8^{\text {th }}$ ed. W. H. Freeman and Company Publishers: New York, NY.

Jürgens, N. (1996). Psammophorous plants and other adaptations to desert ecosystems with high incidence of sandstorm. Fedes Repertorium, 107, 345-359.

Lev-Yadun, S. (2006). Defensive functions of white colouration in coastal and dune plants. Isreal Journal of Plant Sciences, 54, 317-325.

LoPresti, E. F., Grof-Tisa, P., Robinson, M. Godfrey, J., \& R. Karban. (2018). Entrapped sand as a plant defence: Effects on herbivore performance and preference. Ecological Entomology, 43, 154-161.

LoPresti, E. F., \& R. Karban. (2016). Chewing sandpaper: Grit, plant apparency, and plant defense in sand-entrapping plants. Ecology, 97(4), 826-833.

Lucas, P. W., van Casteren, A., Al-Fadhalah, K., Almusallam, A. S., Henry, A. G., Micheal, S., Watzke, J., Reed, D. A., Diekwisch, T. G. H., Strait, D. S., \& Atkins, A. G. (2014). The role of dust, grit and phytoliths in tooth wear. Annales Zoologici Fennici, 51(1/2), 143-152.

Massey, F. P., \& Hartley, S. E. (2009). Physical defences wear you down: Progressive and irreversible impacts of silica on insect herbivores. Journal of Animal Ecology, 78(1), 281291.

Neinhuis, C., Müller-Doblies, U., \& Müller-Doblies, D. (1996). Psammophora and other sandcoated plants from South Africa. Fedes Repertorium, 107, 549-555. 